RU Оценка запаса лексических единиц в связном высказывании детей дошкольного возраста с задержкой психического развития

\author{
Ходякова А. С., Грузина Е. В.
}

Аннотация. Цель исследования - обобщение результатов экспериментального изучения особенностей речемыслительной деятельности дошкольников с особыми образовательными потребностями (с задержкой психического развития (ЗПР)) в рамках исследования лексических единиц речи в связном высказывании. В статье представлены научно-теоретические основы развития и совершенствования изучения запаса лексических единиц в связном высказывании дошкольников; проанализированы и обобщены результаты исследования речемыслительной деятельности дошкольников данной категории. Научная новизна исследования заключается в разработке методики изучения запаса лексических единиц в связном высказывании дошкольников с ЗПР в дистанционном формате путем анкетирования. В результате качественного и количественного анализа особенностей речевого развития детей обогащен исследовательский материал по изучению вербальных и невербальных психических процессов у дошкольников с ЗПР, особенностей их коммуникативного развития.

\title{
Assessing Lexical Richness in Spontaneous Speech of Pre-schoolers with Mental Retardation
}

\author{
Khodyakova A. S., Gruzina E. V.
}

\begin{abstract}
The paper summarizes results of experimental studies on verbal and cogitative activity of preschoolers with special educational needs (mental retardation). Experiments were carried out to assess lexical richness in pre-schoolers' spontaneous speech. The article presents theoretical foundations of studies on pre-schoolers' lexical competence, analyses results of studying verbal and cogitative activity of this category of pre-schoolers. Scientific originality of the research involves developing online assessment methodology to evaluate lexical richness in spontaneous speech of pre-schoolers with mental retardation. The research findings are as follows: qualitative and quantitative analysis of speech development in preschool children with mental retardation allows deeper understanding of their verbal and non-verbal psychic processes, specificity of their communicative development.
\end{abstract}

\section{Введение}

Актуальность исследования. Современная концепция воспитания детей дошкольного возраста и появление требований к характеру и содержанию обучения для данной ступени образования обуславливают необходимость в повышении качества и эффективности развития дошкольников. В связи с тем, что данный процесс имеет сложный и многоаспектный характер, появляются первостепенно значимые вопросы, затрагивающие уровень подготовленности дошкольников к освоению родной речи и языка. Установлено, что полномерное усвоение запаса лексических единиц служит предпосылкой для полноценного овладения грамматическим строем родного языка, развития связной речи и формирования коммуникативных способностей ребенка $[1-3 ; 5 ; 6 ; 8]$.

В рамках данной работы предметом внимания являются вопросы изучения словаря экспрессивной и импрессивной речи, сформированности связной речи дошкольников. Представленные вопросы имеют особое значение для детей дошкольного возраста и младшего школьного возраста, имеющих различные речевые нарушения, в частности для детей с задержкой психического развития (ЗПР).

Для достижения указанной цели исследования необходимо решить следующие задачи:

- изучить научно-теоретические основы развития и совершенствования запаса лексических единиц в связном высказывании детей дошкольного возраста с ЗПР; 
- разработать содержание анкетирования детей дошкольного возраста с ЗПР с помощью их родителей и проанализировать запас лексических единиц в связном высказывании;

- интерпретировать полученные результаты анкетирования детей дошкольного возраста с ЗПР.

Для изучения запаса лексических единиц в связном высказывании в статье применяются следующие методы исследования: аналитический метод; моделирование; анкетирование; Google-анкетирование; педагогический эксперимент; контент-анализ.

Теоретическую базу исследования составляют труды и исследования Л. С. Выготского [6], А. А. Леонтьева [9], С. Л. Рубинштейна [10], Д. Б. Эльконина [11], в которых изложены положения о единстве речевого и психического развития и комплексном подходе к их изучению; Л. Б. Баряевой, Л. В. Лопатиной, Н. Н. Яковлевой [2; 3]; Н. Ю. Боряковой, Т. А. Матросовой [5]; И. Г. Вечкановой [2], И. Н. Лебедевой [2; 8] о положениях специальной педагогики и психологии, в которых описаны многоаспектность познавательного и речевого развития ребенка и представления о структуре речевого дефекта у детей с ЗПР.

Практическая значимость исследования заключается в возможности применения результатов исследования при проведении коррекционной работы по формированию и обогащению лексического запаса, развитию и совершенствованию связной речи детей дошкольного возраста с ЗПР.

\section{Научно-теоретические основы развития и совершенствования запаса лексических единиц в связном высказывании детей дошкольного возраста с задержкой психического развития}

Установлено, что лексическая единица косвенно отождествляется с явлениями и вещами окружающей реальности через понятия разного рода. Наиболее значимым отличительным свойством лексических единиц является непрямая связь семантического устройства лексической единицы с действиями, процессами, явлениями и вещами, находящимися в объективной реальности (Л. С. Выготский [6], А. А. Леонтьев [9], С. Л. Рубинштейн [10]).

Ряд специалистов отмечает, что на словарную единицу в лексическом значении влияет языковой фактор, суть которого заключается в конкретизации запаса лексических единиц с помощью грамматической структуры языка [1; 3; 5]. Стоит обратить внимание и на позицию, указывающую на тот факт, что расширение лексического запаса необходимо осуществлять благодаря использованию лексических единиц в речемыслительной деятельности таким образом, чтобы их смысл был связан со знакомыми предметами/действиями, наряду с их качественными признаками $[1 ; 2 ; 5 ; 8]$.

Результаты исследовательских работ обосновывают применение обиходных лексических единиц в повседневной жизни детей тем, что употребление абстрактных понятий, которые мало знакомы и понятны дошкольникам, запоминаются медленнее, так как не имеют под собой вещественного подкрепления [1]. Ввиду того, что лексика представляет собой одну из составных частей родного языка, она предполагает ситуативный характер использования. Так, восприятие действительности дети осуществляют посредством слуха, зрения и личностной речи, поскольку они используют и внешний диалог, и внутренний монолог [6].

Обогащение лексического запаса в рамках коррекционно-логопедической работы интегрируется с таким образовательными областями, как «Речевое развитие» и «Социально-коммуникативное развитие» [3]. Проводя обучение в указанном направлении, учителя-дефектологи и учителя-логопеды акцентируют внимание на формировании структуры значения слова, исходя из признаков сходства, противопоставления, аналогии [1; 5; 8]. В частности, проводится работа над многозначностью слова.

В процессе развития связного высказывания дошкольников предварительно осуществляется объединение слов по той или иной тематике, что в дальнейшем способствует проведению занятий по дифференциации слов внутри семантического поля. Вышеописанное является одним из ведущих направлений коррекционнопедагогической работы с детьми с особыми образовательными потребностями: развитие коммуникативной функции речи, формирование связной монологической речи [3; 4; 8]. В рамках данного направления развития дошкольников обучают вести беседу на знакомые им темы, описывать предмет или явление [1].

Таким образом, аналитический обзор литературных источников продемонстрировал, что дети дошкольного возраста с ЗПР испытывают серьезные трудности в ходе развития лексической стороны речи, что не может не отразиться на речемыслительной деятельности, способностях к речевой коммуникации, а также когнитивных возможностях.

\section{Организация процесса анкетирования, целевая аудитория, содержание анкеты и критерии оценивания ответов}

Экспериментальное изучение лексического строя речи у дошкольников осуществлялось нами дистанционно посредством метода анкетирования 20 семей, воспитывающих детей с разным уровнем речевого и когнитивного развития, в период с апреля по июнь 2020 г. Дошкольники обучаются на базе дошкольных образовательных организаций г. Москвы и Московской области (г. Мытищи).

Мы привлекали к участию в исследовании респондентов через родительские сообщества и чаты дошкольных организаций в социальных сетях: WhatsApp, ВКонтакте. Представленный метод проведения педагогического эксперимента обусловлен закрытием дошкольных образовательных учреждений на карантин. 
Ниже представлены пункты анкеты:

1. Отметьте лексические темы, которые знает Ваш ребенок (данный пункт анкеты подразумевает ответ родителя без участия детей). В перечне были предложены следующие лексические темы: овощи, фрукты, посуда, домашние животные, дикие животные, птицы, насекомые, обувь, мебель, части тела, деревья, грибы, профессии, транспортные средства, эмоции, игрушки.

2. Попросите ребенка назвать 4-5 слов из каждой лексической темы.

3. Отметьте, какая лексическая тема ребенку наиболее интересна.

4. Попросите ребенка назвать сказки/рассказы, которые он знает.

5. Попросите Вашего ребенка рассказать сказку/рассказ об овощах, которую он знает (рассказ составляется самостоятельно ребенком).

6. Попросите Вашего ребенка рассказать сказку/рассказ о диких животных, которую он знает (рассказ составляется самостоятельно ребенком).

7. Попросите Вашего ребенка рассказать сказку/рассказ о зиме, которую он знает (рассказ составляется самостоятельно ребенком).

8. Укажите, каких персонажей из сказок/рассказов знает Ваш ребенок.

9. Попросите ребенка назвать основных персонажей любимой сказки.

10. Попросите ребенка составить рассказ про каждого персонажа любимой сказки/рассказа. Запишите этот рассказ дословно [4].

Анкета была предложена в определенном формате, который давал возможность родителям сразу фиксировать ответы и выполнять различные знаковые действия. Распространение анкеты осуществлялось по электронной почте, что давало возможность участникам эксперимента распечатать и заполнить её от руки. Кроме этого, нами был предусмотрен онлайн-формат заполнения анкеты, которая была представлена в виде Google Формы. В качестве образца была заполнена одна анкета и отправлена родителям с пометкой «ПРИМЕР» [Там же].

Отметим, что в целях проведения более тщательного и точного изучения ответов детей мы просили родителей записывать ответы детей дословно. Для выполнения данного условия исследования нами было предложено фиксировать ответы и рассказы детей с помощью доступных технических средств (аудио- или видеозаписи).

Обратим внимание на то, что формат записи коротких аудиозаписей/голосовых сообщений оказался самым удобным для участников эксперимента. Подобные аудио сообщения родители отсылали сериями непосредственно в переписке мессенджера WhatsApp. Проведение исследования в дистанционном формате предусматривало предварительное согласование с родителями анонимности и закрытости использования полученных результатов.

Пункты анкеты 1, 3 и 8 не входили в систему оценивания ввиду того, что они были включены в опросный лист для мотивации родителей к анализу речевых умений и навыков детей. Интерпретация речевых высказываний детей осуществлялась в два этапа.

В рамках первого этапа проводилось исследование запаса лексических единиц. Система оценки осуществлялась следующим образом:

- 3 балла - правильно выполненное задание;

- 2 балла - задание было выполнено с частичной помощью взрослого;

- 1 балл - задание выполнено полностью с помощью взрослого;

- 0 баллов - невыполненное задание.

Примечание: 1 балл отнимался при ошибочном выполнении задания.

На втором этапе нами было проведено изучение уровня владения произвольной связной речью детей (пункты анкеты 5, 6, 7, 10). Оценка заданий, связанных с составлением рассказов, включала наличие тех свойств произвольного речевого высказывания, которыми оно обладает, а именно намеренность, воспринимаемость, доступность, завершенность, связность и цельность [8]. Кроме того, особое внимание было уделено наличию смысловых пропусков и повторов в рамках составленных рассказов.

Система оценивания рассказов составлена с учетом схемы, предложенной В. П. Глуховым для оценки уровня воспроизведения готового текста [7]. Составленные рассказы дошкольников рассматривались с точки зрения следующих уровней:

1 уровень - «хорошо»; рассказ составлен самостоятельно; характеризуется связностью и последовательностью изложения; соблюдаются нормы грамматического строя речи. Оценивается в 5 баллов.

2 уровень - «удовлетворительно»; составление рассказа осуществляется с помощью взрослого (побуждения, уточняющие вопросы); в процессе рассказывания наблюдаются нарушения связности текста, частичные искажения структуры предложений; отмечается отсутствие художественно-стилистических элементов. Оценивается в 4 балла.

3 уровень - «недостаточно»; для составления рассказа требуются повторные наводящие вопросы; наблюдаются смысловые пропуски и повторы, а также нарушения связности речевого высказывания. Оценивается в 3 балла.

4 уровень - «низкий»; рассказ составлен по вопросам; отмечаются смысловые ошибки, несоблюдение связности, бедность и однообразие языковых средств. Оценивается в 2 балла.

5 уровень - задание не выполнено; оценивается в 1 балл. 


\section{Описание и интерпретирование результатов анкетирования}

По результатам исследования заполненных анкет дети были разделены на экспериментальную (10 человек с ЗПР) и сравнительную группу (10 человек с нормативным развитием). Основываясь на вышеописанной системе оценивания, проведенный анализ экспериментальных данных продемонстрировал результаты, которые были разделены на две части.

За первую часть (задания по лексическим темам: $2,4,9)$ детям экспериментальной группы было начислено в среднем 28 баллов, а детям сравнительной группы - 49 баллов.

Результаты выполнения второй части заданий (задания на составление рассказа: $5,6,7,10$ ) показали, что экспериментальная группа в среднем получила 16 баллов, сравнительная группа - 28 баллов.

Нами был отмечен тот факт, что при заполнении пунктов анкеты 1,3 и 8, где не требовались ответы детей, родители отмечали, что дети знают практически все лексические темы. Однако при исследовании ответов воспитанников было установлено, что дети 5-6 лет с ЗПР практически не называли насекомых, деревья, профессии, цветы, допускали ошибки в назывании фруктов и овощей.

Так, некоторые дошкольники затруднялись назвать лексические единицы по темам «Игрушки», «Одежда», «Обувь». В лексической теме «Профессии» не были названы профессии, которые дети могли наблюдать в окружающем социуме, например, дворника, полицейского, пожарного, продавца. Особую сложность для дошкольников представляла тема «Транспортные средства». В данной категории слов не были названы такие виды транспортных средств, как троллейбус, теплоход, трамвай. Особый интерес для детей представляла лексическая тема «Игрушки», в рамках выполнения заданий на данную тематику у дошкольников наблюдалось желание называть предметы, рассказывать о них, делиться своими впечатлениями.

Характеризуя самостоятельные высказывания испытуемых с ЗПР, мы выделили ряд отличительных особенностей: нарушения в программировании текста; снижение контроля над смысловой стороной высказывания вследствие чего появляются смысловые пропуски, повторы; затруднения в выделении основных и второстепенных признаков, качеств предмета; множественные синтаксические и грамматические ошибки, которые выражаются в неверном употреблении родовых, числовых и падежных форм существительных, прилагательных, местоимений; ошибки в согласовании глаголов с существительными и местоимениями; нарушение связности и цельности произвольного высказывания.

\section{Заключение}

Изучение запаса лексических единиц в связном высказывании дошкольников с ЗПР осуществлялось в деятельности, где речь и мышление составляют единое целое. В результате проведенного исследования разработано содержание анкет для проведения диагностики речемыслительной деятельности детей с ЗПР в дистанционном формате. Интерпретация полученных данных позволила выявить специфические особенности запаса лексических единиц и связного высказывания дошкольников данной категории, связанные с недостаточным когнитивным развитием. Результаты эксперимента предоставляют возможность разрабатывать модели коррекционно-педагогического воздействия с целью оптимизации процесса обучения детей с особыми образовательными потребностями, формирования коммуникативных навыков, оказания помощи в их социализации, что является одной из ведущих задач Федерального государственного образовательного стандарта дошкольного образования.

Перспектива дальнейших исследований представляется в разработке модели коррекционно-педагогического воздействия на формирование коммуникативных навыков дошкольников с ЗПР.

\section{Источники | References}

1. Алексеева М. М., Яшина Б. И. Методика развития речи и обучения родному языку дошкольников. М.: Академия, 2000. 400 с.

2. Баряева Л. Б., Вечканова И. Г., Галлямова Ю. С., Ивлева М. Г., Кондратьева С. Ю., Лебедева И. Н., Лопатина Л. В., Макоедова Г. В., Яковлева Н. Н. Дети с задержкой психического развития: экспериментальное исследование и направления коррекционной работы: коллективная монография. М.: Добрый мир, 2018. 331 с.

3. Баряева Л. Б., Волосовец Т. В., Гаврилушкина О. П., Голубева Г. Г., Кириллов И. Л., Кутепова Е. Н., Лопатина Л. В., Овчинникова Т. С., Славин С. С., Яковлева Н. Н. Адаптированная основная образовательная программа дошкольного образования детей с тяжёлыми нарушениями речи. С методическими рекомендациями. М.: Просвещение, 2019. 335 с.

4. Баряева Л. Б., Грузина Е. В. Изучение лексического строя речи дошкольников с общим недоразвитием речи: ответы детей и их родителей // Непрерывное образование лиц с особыми образовательными потребностями: вызовы и инновационные практики: сб. научных статей по материалам научно-практической конференции. М.: Добрый мир, 2020. С. 32-37.

5. Борякова Н. Ю., Матросова Т. А. Изучение и коррекция лексико-грамматического строя речи у детей с недостатками познавательного и речевого развития (на примере глагольной лексики, словоизменения глаголов и построения простых распространенных предложений). М.: АТТИКА, 2010. 200 с. 
6. Выготский Л. С. Игра и ее роль в психическом развитии ребёнка // Вопросы психологии. 1966. № 6. С. 74-75.

7. Глухов В. П. Методика формирования связной речи дошкольников с ОНР. М.: АРКТИ, 2004. 240 с.

8. Лебедева И. Н. Развитие связной речи дошкольников. Обучение рассказыванию по картине: учебно-методическое пособие. СПб.: ЦДК проф. Л. Б. Баряевой, 2009. 200 с.

9. Леонтьев А. А. Слово о речевой деятельности. М.: Наука, 1965. 425 с.

10. Рубинштейн С. Л. Психология речи: сборник статей. Л., 1941. 304 с. +2 вкл. л. ил.

11. Эльконин Д. Б. Избранные психологические труды. М.: Педагогика, 1989.560 с.

\section{Информация об авторах | Author information}

\section{RU Ходякова Александра Сергеевна ${ }^{1}$} Грузина Елена Валерьевна ${ }^{2}$

${ }^{1}$ Московский государственный областной университет;

Московский городской педагогический университет

${ }^{2}$ Московский городской педагогический университет

\section{EN Khodyakova Alexandra Sergeevna ${ }^{1}$} Gruzina Elena Valeryevna ${ }^{2}$

${ }^{1}$ Moscow Region State University; Moscow City University

${ }^{2}$ Moscow City University

19-hodyakova@mail.ru, 2elenavat@yandex.ru

\section{Информация о статье | About this article}

Дата поступления рукописи (received): 27.03.2021; опубликовано (published): 30.06.2021.

Ключевые слова (keywords): запас лексических единиц; связное высказывание; дети дошкольного возраста; задержка психического развития (ЗПР); lexical richness; statement; pre-schoolers; mental retardation. 